\title{
Anatomia e ultra-estrutura do pulvino primário de Pterodon pubescens Benth. (Fabaceae - Faboideae)
}

\author{
SÍLVIA R. MACHADO ${ }^{1,2}$ e TATIANE M. RODRIGUES ${ }^{1}$
}

(recebido: 6 de novembro de 2002; aceito: 20 de novembro de 2003)

\begin{abstract}
Anatomy and ultrastructure the primary pulvinus of Pterodon pubescens Benth. (Fabaceae - Faboideae)). The anatomy and ultrastructure of Pterodon pubescens primary pulvinus were studied to verify if slow leaf movements are associated with pulvinus cells features. Pulvini samples deriving from leaf with open and closed leaflets were prepared following usual techniques using light and electron microscopy. The pulvinus has a unisseriated epidermis covered by a thick cuticle and many trichomes, cortex with several layers of parenchyma cells (motor cells), a central vascular core surrounded by septate fibers, and a reduced pith. Cortical cells features change with the turgescence degree, showing alteration in the cell size and shape, cell wall thickness, frequency and arrangement of plasmodesmata, vacuole content and number and cytoplasm density. Septate fibers around the phloem were described for the first time in pulvini. The wide occurrence of plasmodesmata, the apoplastic barriers absence and the lignification scarcity (only present in xylem vessels) indicate a continuity, both simplastic and apoplastic, from the epidermis to the vascular tissue of the pulvinus. In Pterodon pubescens, primary pulvinus features are compatible with slow movement pulvini; the features shared to speedy movement pulvini are the presence of vacuoles with phenolic substances in the cortical cells and amiloplasts in the endodermal cells. Movements caused by $P$. pubescens primary pulvinus are associated with changes in both the apoplastic (wall infoldings) and symplastic (vacuolar reorganization).
\end{abstract}

Key words - anatomy, Fabaceae, Pterodon pubescens, primary pulvinus, ultrastructure

RESUMO - (Anatomia e ultra-estrutura do pulvino primário de Pterodon pubescens Benth. (Fabaceae - Faboideae)). A anatomia e ultra-estrutura do pulvino primário de Pterodon pubescens foram estudadas para verificar se os movimentos lentos de suas folhas estão associados às características celulares do pulvino. Amostras de pulvinos provenientes de folhas com folíolos abertos e fechados foram preparadas segundo técnicas usuais em microscopia de luz e eletrônica. O pulvino é constituído por epiderme unisseriada recoberta por cutícula espessa e tricomas tectores, córtex com diversas camadas de células parenquimáticas (ou motoras), feixe vascular central rodeado por bainha de fibras septadas e medula reduzida. As características das células motoras variam de acordo com o grau de turgescência do pulvino, ocorrendo alterações no tamanho e forma das células, na espessura das paredes celulares, na freqüência e organização dos plasmodesmos, no conteúdo e número de vacúolos e na densidade do citoplasma. Fibras septadas ao redor do floema estão sendo descritas pela primeira vez em pulvinos. A ampla ocorrência de plasmodesmos, a ausência de barreiras apoplásticas e a escassez de lignificação (presente unicamente nos vasos do xilema) indicam uma continuidade, simplástica e apoplástica, desde a epiderme até o tecido vascular do pulvino. Em P. pubescens, as características do pulvino primário são compatíveis com as de pulvinos que apresentam movimentos lentos; as características compartilhadas com pulvinos de movimentos rápidos são a presença de vacúolos com substâncias fenólicas nas células corticais e amiloplastos na endoderme. Os movimentos promovidos pelo pulvino primário de $P$. pubescens estão associados a mudanças nos compartimentos apoplástico (dobramentos das paredes celulares) e simplástico (reorganização vacuolar).

Palavras-chave - anatomia, Fabaceae, Pterodon pubescens, pulvino primário, ultra-estrutura

\section{Introdução}

Pterodon pubescens Benth., uma leguminosa arbórea nativa dos cerrados, possui folhas compostas pinadas cujos folíolos apresentam movimentos heliotrópicos diários. Nessa espécie, os movimentos foliares são lentos e reversíveis e resultam da curvatura dos pulvinos primário e secundário e, comprovadamente,

\footnotetext{
1. Universidade Estadual Paulista, Instituto de Biociências, Departamento de Botânica, Campus de Botucatu, Caixa Postal 510, 18618-000 Botucatu, SP, Brasil.

2. Autor para correspondência: smachado@ibb.unesp.br
}

em condições adversas mantêm as reações fotoquímicas em taxas elevadas, embora a radiância seja drasticamente reduzida (Caldas et al. 1997).

O mecanismo fisiológico básico do movimento das folhas em diferentes espécies de leguminosas é bem conhecido, tendo sido relatado que os movimentos foliares resultam de variações na pressão de turgor nas células do parênquima cortical, ou células motoras (Toriyama 1953), localizadas em lados opostos do pulvino, chamados zonas extensora e flexora (FleuratLessard \& Roblin 1982, Fleurat-Lessard 1988, Moysset \& Simón 1991) e são, de algum modo, controlados por fitocromo (Taiz \& Zeiger 1998). Semelhante aos 
movimentos das células-guarda, as mudanças no turgor das células motoras dependem do fluxo de íons potássio e cloreto através das membranas celulares, juntamente com fluxos de água, afetando assim as propriedades osmóticas dessas células.

Os estudos apontam uma continuidade, tanto simplástica quanto apoplástica, entre as células do córtex e os tecidos vasculares; contudo, o caminho exato desta redistribuição iônica entre as diferentes regiões do córtex e, especialmente através dos tecidos vasculares, é pouco conhecido (Moysset \& Simón 1991). Trabalhos realizados com diferentes espécies de leguminosas têm evidenciado que esses eventos fisiológicos estão correlacionados com características estruturais do pulvino, principalmente a existência de um arranjo estrutural que assegura mudanças celulares rápidas, além de características estruturais particulares das células motoras que facilitam tanto a sua deformação quanto o fluxo de íons, as quais em conjunto, regulam os movimentos foliares (Satter et al. 1970, Morse \& Satter 1979, Campbell \& Garber 1980, Fleurat-Lessard 1981, Fleurat-Lessard \& Roblin 1982, Fleurat-Lessard \& Satter 1985, Moysset \& Simón 1991).

Na literatura disponível, nota-se que a maioria das informações sobre a estrutura do pulvino é restrita às células do parênquima cortical de poucas espécies de leguminosas, em especial Mimosa pudica L. que apresenta movimentos rápidos (Fleurat-Lessard 1981, 1988). Com relação a $P$. pubescens, informações detalhadas sobre a estrutura do pulvino não foram encontradas em literatura. Com o objetivo de verificar se os eventos fisiológicos relacionados aos movimentos foliares em $P$. pubescens podem estar associados às características estruturais do pulvino primário, a sua anatomia foi investigada com ênfase nas características das células epidérmicas, corticais e dos tecidos vasculares.

\section{Material e métodos}

Material botânico - As amostras de pulvino primário foram retiradas de folhas completamente expandidas, coletadas de exemplares adultos ocorrentes em cerrado localizado no município de Botucatu-SP $\left(22^{\circ} 55^{\prime} \mathrm{S}\right.$ e $\left.48^{\circ} 30^{\prime} \mathrm{W}\right)$. Ramos férteis foram herborizados e depositados no Herbário "Irina Delanova de Gemtchujnicov" (BOTU), do Departamento de Botânica, Instituto de Biociências, UNESP, Campus de Botucatu, sob número 23895.

Para as análises anatômicas e ultra-estruturais, foram feitas duas amostragens: pulvino de folhas com folíolos abertos (expostas ao sol) e pulvino de folhas com folíolos fechados (mantidas no escuro após a coleta).
Microscopia de luz - Amostras retiradas das regiões proximal, mediana e distal do pulvino foram imediatamente fixadas em FAA 50 (Johansen 1940), desidratadas em série etílica, incluídas em resina glicol-metacrilato e seccionadas em micrótomo rotativo; os cortes com $6 \mu \mathrm{m}$ de espessura foram corados com Azul de Toluidina 0,05\%, pH 3,8 (O’Brien et al. 1964) e montados em Permount. Cortes feitos a mão livre obtidos com auxílio de lâminas de barbear, foram corados com Sudan IV para identificar substâncias lipídicas; Cloreto Férrico a 10\% para substâncias fenólicas; Lugol para detecção de amido (Johansen 1940) e Vermelho de Rutênio a 0,02\% aquoso, para polissacarídeos diversos e pectinas (Jensen 1962).

Microscopia eletrônica de varredura (MEV) - Amostras de pulvinos, intactos ou fragmentados, foram fixadas em glutaraldeído $2,5 \%$ tampão fosfato $0,1 \mathrm{M}, \mathrm{pH} 7,3$ por 24 horas, pós-fixadas em tetróxido de ósmio a $0,5 \%$ por 1 hora, lavadas em água destilada, desidratadas em série etílica e secadas em "ponto crítico" utilizando carbono líquido. As amostras foram montadas com cola de prata e esmalte sobre suporte de alumínio e metalizadas com ouro, formando-se uma camada de $10 \mathrm{~nm}$ de espessura. O material foi analisado em microscópio eletrônico de varredura Philips SEM 515, $20 \mathrm{kV}$.

Microscopia eletrônica de transmissão (MET) - Amostras retiradas da região mediana do pulvino foram fixadas em

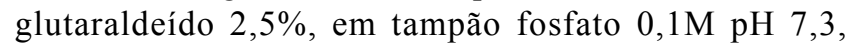
pós-fixadas em tetróxido de ósmio, desidratadas em série crescente de soluções de acetona, embebidas e incluídas em Araldite. Os cortes ultra-finos foram contrastados com citrato de chumbo e acetato de uranila e observados em microscópio eletrônico de transmissão Philips EM 100, 80kV.

\section{Resultados}

Morfologia do pulvino - O pulvino primário das folhas de Pterodon pubescens Benth. é cilíndrico, mede cerca de 3 a $4 \mathrm{~mm}$ de comprimento e $2 \mathrm{~mm}$ de diâmetro, apresentando face ventral plana a ligeiramente côncava e face dorsal convexa. A superfície do pulvino é estriada e se apresenta revestido por numerosos tricomas tectores unisseriados (figura 1), eretos, de base estreita e ápice pontiagudo e superfície variando de lisa a verrucosa (figura 2). Estômatos não foram observados. Em geral, os sulcos transversais conferem ao pulvino um aspecto ondulado (figura 1). A quantidade e a profundidade dos sulcos variam de acordo com a orientação do pulvino: nas folhas abertas, o pulvino se apresenta em posição horizontal e os sulcos são mais numerosos e mais profundos na superfície adaxial; nas folhas fechadas, o pulvino se apresenta em posição vertical e os sulcos são mais pronunciados na superfície abaxial.

Anatomia do pulvino - O pulvino, em corte transversal realizado na região mediana, apresenta formato 
dorsiventral, superfície irregular com reentrâncias e saliências, epiderme unisseriada, córtex parenquimático onde se observam cavidades secretoras, feixe vascular central rodeado por uma espessa bainha de fibras e medula reduzida (figura 3 ).

A epiderme é formada por células papiliformes que se dispõem em fileiras regulares, sendo recoberta por cutícula lisa. $\mathrm{O}$ córtex é constituído por cerca de 30 camadas de células parenquimáticas de tamanhos e formatos variáveis (figura 3); na região mais externa do córtex, as células têm disposição compacta, enquanto que na mais interna, ocorrem espaços intercelulares pequenos. As paredes dessas células são relativamente espessadas, apresentam contorno variável e pontoações simples evidentes (figura 4). As características das células corticais variam nas diferentes regiões do córtex e de acordo com a orientação e grau de turgescência do pulvino. No córtex externo do pulvino fechado, as células são geralmente poliédricas e mostram paredes sinuosas, com espessura irregular (figura 5), enquanto que no pulvino aberto, as células possuem paredes de espessura e contorno mais uniformes (figura 6). Além disso, a região mais externa do córtex apresenta dois tipos celulares com base na afinidade dos vacúolos ao Azul de Toluidina e reação ao Cloreto Férrico: células com conteúdo translúcido e células mais densas, geralmente dispostas em aglomerados (figura 3), preenchidas por substâncias identificadas como sendo compostos fenólicos. Na última camada do córtex interno (figuras 6 e 8), as células são alongadas tangencialmente, apresentam disposição compacta e contem grãos de amido e cristais prismáticos de oxalato de cálcio.

O sistema vascular central, em corte transversal na região mediana do pulvino (figura 3), consiste de um só feixe colateral em forma de arco com as extremidades livres ou fusionadas, circundado por seis a sete camadas de células losangulares pequenas (figuras 5, 6), com paredes pecto-celulósicas espessadas, citoplasma abundante e núcleo conspícuo com nucléolo evidente (figura 7), sendo identificadas como fibras septadas (figura 8) de origem pericíclica. O floema é formado por elementos de tubo crivado, células companheiras e células do parênquima axial, todos arranjados em pequenos grupos circundados por células do parênquima radial (figura 10); fibras e esclereídes estão ausentes. No xilema, os elementos de vaso estão associados com células do parênquima e fibras não lignificadas. Raios parenquimáticos são evidentes nos dois tecidos, sendo mais desenvolvidos no floema (figuras 9, 10), podendo atingir as fibras septadas (figura 7).
Ultra-estrutura do pulvino

Células epidérmicas - As células epidérmicas apresentam parede periclinal externa revestida por cutícula bastante espessa, onde se observam dois estratos distintos: um mais externo, elétron-lucente, de aspecto homogêneo, constituindo a cutícula propriamente dita e outro mais interno e denso, lamelado e de aspecto heterogêneo, contendo ramificações elétron-densas de natureza péctica, constituindo a camada cuticular (figuras 11, 12). As paredes anticlinais são mais espessas no polo distal das células, onde apresentam uma intensa incrustação de cutina formando flange cuticular; no pólo proximal, são mais delgadas e sinuosas e possuem plasmodesmos. A parede periclinal interna também é espessa e apresenta aspecto fenestrado devido a presença de numerosos plasmodesmos amplos (figura 13). O citoplasma das células epidérmicas é abundante e contem organelas típicas, sendo observados mitocôndria (figura 12), dictiossomos com vesículas adjacentes, retículo endoplasmático (figura 14), e plastídeos elípticos com estroma denso e sistema de membranas internas pouco desenvolvido. Com relação ao vacuoma, as células podem ser univacuoladas ou apresentar vários vacúolos pequenos com acúmulos de material denso (figura 14).

Células corticais - As características da parede, citoplasma e vacuoma das células corticais ou motoras variam nas diferentes regiões do córtex e de acordo com o grau de turgescência do pulvino. No pulvino fechado, em geral, as células do córtex externo são multivacuoladas, com paredes sinuosas ou intensamente dobradas e citoplasma relativamente abundante e pouco denso, onde as organelas se apresentam dispersas (figuras 15, 16). No pulvino aberto, as células mostramse univacuoladas, com paredes de contorno regular a levemente sinuoso, núcleo elíptico e citoplasma reduzido a uma fina camada periférica (figura 17). Os vacúolos contêm material floculado (vacúolo coloidal) ou acúmulos de substâncias elétron-densas (vacúolo taninífero). Plasmodesmos amplos e ramificados, mitocôndrias, dictiossomos, retículo endoplasmático, estruturas vesiculares e gotas de óleo dispersas foram observados em todas as células do córtex (figura 16) além de cloroplastos (figuras 17, 18). Na última camada do córtex interno, ou camada endodermal, todas as células caracteristicamente contêm citoplasma abundante, núcleo elíptico com nucléolo evidente adjacente à parede tangencial externa, e amiloplastos margeando a face interna das células (figura 19). Nas paredes tangenciais destas células, em contato tanto com as células do córtex (figura 19) quanto com as fibras septadas (figuras 21, 

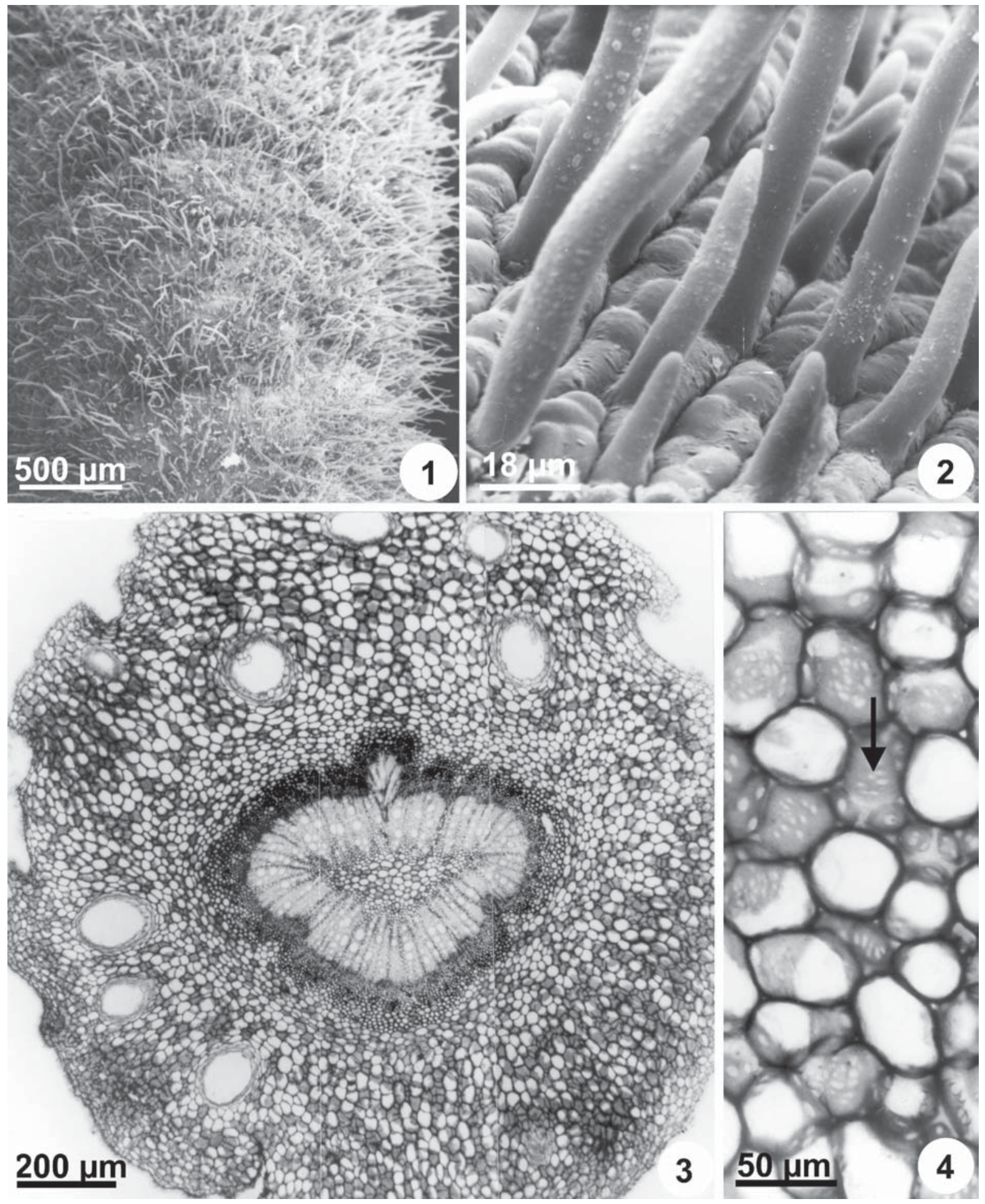

Figuras 1-4. Região mediana do pulvino primário de P. pubescens. 1-2. MEV. 1. Superfície do pulvino fechado mostrando sulcos transversais e tricomas tectores. 2. Detalhe mostrando tricomas tectores com superfície lisa ou verrucosa. 3. Secção transversal do pulvino mostrando superfície com reentrâncias e saliências, córtex amplo com cavidades secretoras, feixe vascular central e medula reduzida. 4. Detalhe de células corticais mostrando pontoações simples (seta).

Figures 1-4. P. pubescens primary pulvinus median region. 1-2. MEV. 1. Closed pulvinus surface showing transversal grooves and protective trichomes. 2. Detail showing protective trichomes with smooth or warty surface. 3. Pulvinus transversal section showing irregular surface, developed cortex with secretory cavities, central vascular bundle, and reduced medullar parenchyma. 4. Detail of cortical cells showing simple pits (arrow). 

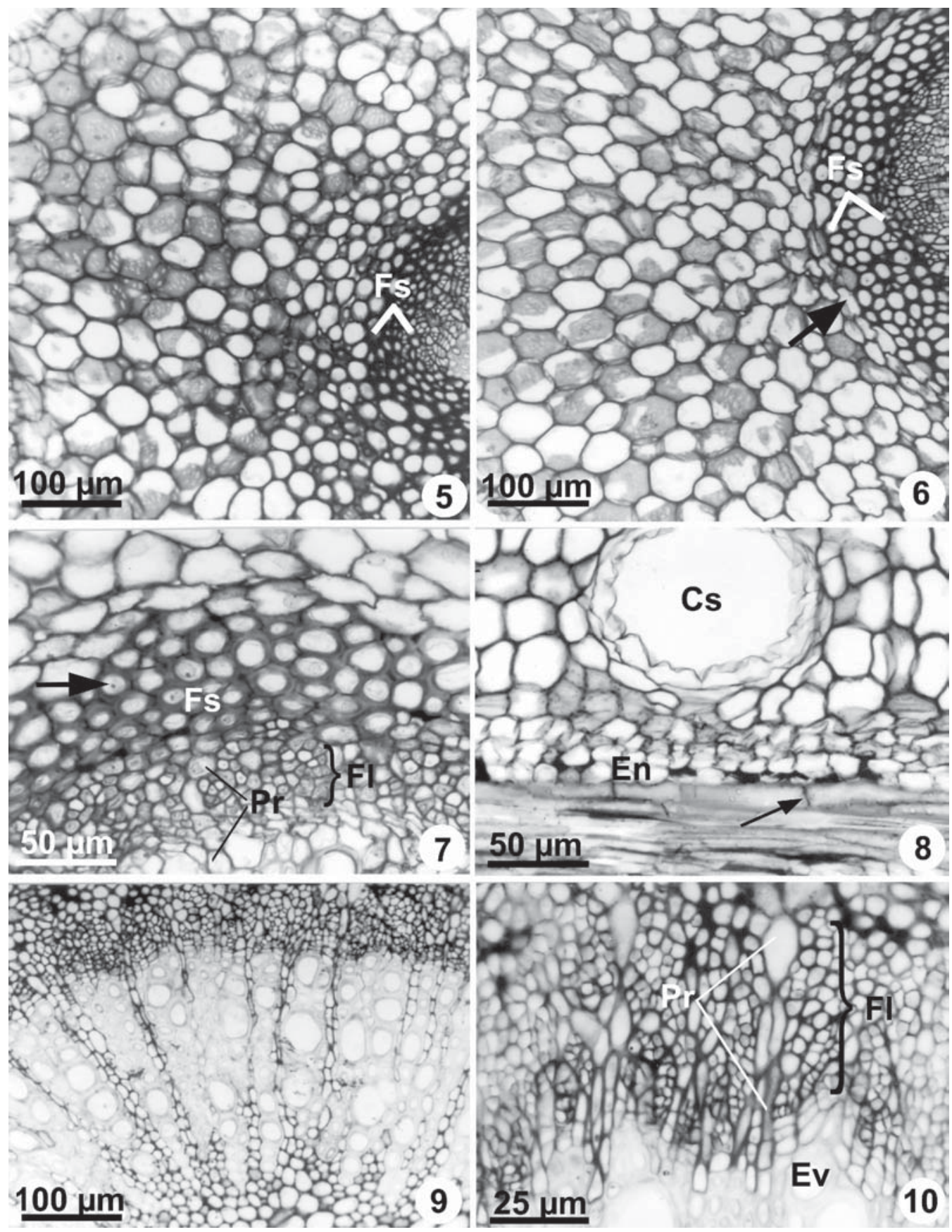

Figuras 5-10. Região mediana do pulvino primário de P. pubescens. 5. Secção transversal do pulvino fechado mostrando células corticais comprimidas e bainha de fibras ao redor do floema. 6. Secção transversal de pulvino aberto mostrando células corticais túrgidas. A seta indica endoderme. 7. Fibras pericíclicas septadas, em secção transversal, mostrando núcleo (seta) com nucléolo evidente. 8. Fibras pericíclicas septadas, em seç̧ão longitudinal, com septo evidente (seta). 9. Feixe vascular, em secção transversal, com raios parenquimáticos no floema e xilema. 10. Detalhe da figura 9 , mostrando parênquima radial com células conspícuas no floema. $(\mathrm{Cs}=$ cavidade secretora; $\mathrm{En}=$ endoderme; $\mathrm{Ev}=$ elemento de vaso; $\mathrm{Fl}=$ floema; Fs = fibras septadas; $\operatorname{Pr}=$ parênquima radial).

Figures 5-10. P. pubescens primary pulvinus median region. 5. Closed pulvinus transversal section showing compressed cortical cells and fibers sheath around the phloem. 6. Open pulvinus transversal section showing turgid cortical cells. The arrow indicates endodermis. 7. Septate pericyclic fibers, in transversal section, showing nucleus (arrow) with nucleolus. 8. Septate pericyclic fibers, in longitudinal section, with visible septum (arrow). 9. Vascular bundle transversal section showing parenchyma rays in the xylem and phloem. 10. Detail of the figure 9, showing radial parenchyma with conspicuous cells in the phloem. $(\mathrm{Cs}=$ secretory cavity; $\mathrm{En}=$ endodermis; $\mathrm{Ev}=$ vessel element; $\mathrm{Fl}=$ phloem; $\mathrm{Fs}=$ septate fibers; $\mathrm{Pr}=$ radial parenchyma $)$. 


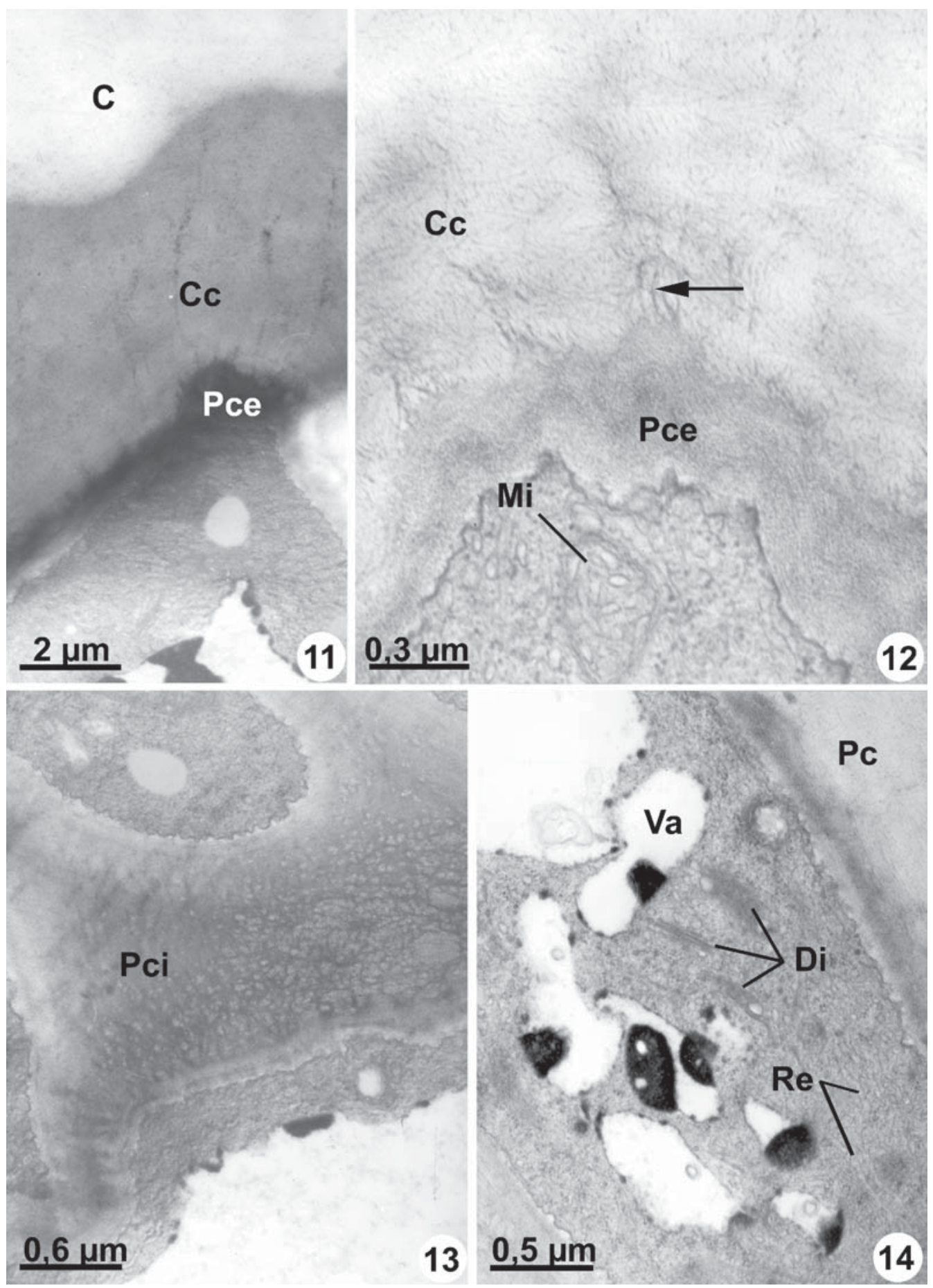

Figuras 11-14. Epiderme do pulvino primário de P. pubescens (MET). 11. Parede periclinal externa revestida por cutícula com dois estratos distintos: cutícula propriamente dita e camada cuticular mais densa. 12. Detalhe da figura 11, mostrando ramificações de substâncias pécticas (seta) na camada cuticular. 13. Parede periclinal interna com aspecto fenestrado. 14. Parte de uma célula epidérmica com citoplasma abundante. $(\mathrm{C}=$ cutícula; $\mathrm{Cc}=$ camada cuticular; $\mathrm{Di}=$ dictiossomo; $\mathrm{Mi}=$ mitocôndria; $\mathrm{Pc}=$ parede celular; $\mathrm{Pce}=$ parede periclinal externa; $\mathrm{Pci}=$ parede periclinal interna; $\mathrm{Re}=$ retículo endoplasmático; $\mathrm{Va}=$ vacúolo).

Figures 11-14. P. pubescens primary pulvinus epidermis (TEM). 11. Outer periclinal cell wall covered by cuticle with two different layers: cuticle and dense cuticle layer. 12. Detail of figure 11 showing cuticle layer with dense network (arrow) of pectic compounds. 13. Inner periclinal cell wall with fenestrated aspect. 14. Part of epidermal cell with abundant cytoplasm. $(\mathrm{C}=$ cuticle; $\mathrm{Cc}=$ cuticle layer; $\mathrm{Di}=$ dictyosome $; \mathrm{Mi}=$ mitochondria; $\mathrm{Pc}=$ cell wall $; \mathrm{Pce}=$ outer periclinal cell wall; $\mathrm{Pci}=$ inner periclinal cell wall; $\mathrm{Re}=$ endoplasmic reticulum; $\mathrm{Va}=$ vacuole). 
23), são observados campos de pontoação primários com plasmodesmos simples ou ramificados (figuras 20,21). No citoplasma, ocorrem polirribossomos, mitocôndrias com cristas proeminentes, retículo endoplasmático, dictiossomos, estruturas vesiculares dispersas e vacúolos de tamanhos variáveis (figuras 21, 22).

Sistema vascular

Fibras pericíclicas - Estas células, em secção transversal (figura 23), mostram paredes espessas e lameladas, sendo que a camada parietal mais interna apresenta contorno sinuoso ou ondulado e aspecto laxo; a parede em contato com as células da camada endodermal possui depressões onde se observam numerosos plasmodesmos. Apresentam núcleo conspícuo e de contorno irregular, às vezes lobado, com nucléolo evidente. O citoplasma é abundante e possui ribossomos livres, polirribosomos, retículo endoplasmático, dictiossomos com vesículas, mitocôndrias, gotas de óleo dispersas e plastídeos; os vacúolos são elétron-lucentes e de tamanhos variáveis (figuras 23-25). Conectando as fibras entre si ocorrem campos de pontoação primários com numerosos plasmodesmos (figura 24). Cada septo da fibra é constituído por lamela média e duas paredes de natureza pecto-celulósica interrompidas por numerosos plasmodesmos amplos (figura 25). Nas adjacências dos septos, o citoplasma é mais abundante e denso e, a membrana plasmática sinuosa.

Floema - As células constituintes do floema (figura 26) apresentam paredes pécto-celulósicas espessadas, sendo que os elementos de tubo crivado caracterizam-se pelo maior diâmetro e presença de placa crivada, plastídeo$\mathrm{P}$ e acúmulos de material protéico denso em uma das extremidades. As células companheiras apresentam núcleo grande, citoplasma denso e vacuoma pouco desenvolvido, enquanto que as células parenquimáticas possuem citoplasma periférico e vacúolo único central. Xilema - Os elementos de vaso apresentam-se ladeados por células parenquimáticas e fibras com protoplasto ativo; estas células são reconhecidas ao nível ultraestrutural como elementos fusiformes com vacúolo central mais desenvolvido e paredes mais espessadas; pontoações simples conectam os vasos com as células adjacentes (figura 27). As células parenquimáticas possuem núcleo grande com nucléolo evidente, citoplasma denso e abundante com mitocôndrias volumosas, retículo endoplasmático extensivo, dictiossomos, vesículas de tamanhos variáveis e gotas de óleo dispersas (figuras 27, 28). Conexões via plasmodesmos são observadas entre todas as células vivas do xilema (figura 28 ).

\section{Discussão}

As características morfológicas externas e a organização anatômica do pulvino primário de P. pubescens são comuns às leguminosas já estudadas por diferentes autores (Campbell \& Thomson 1977, Campbell \& Garber 1980, Fleurat-Lessard \& Millet 1984, Fleurat-Lessard 1988, Morse \& Satter 1979, Moysset \& Simón 1991, Satter et al. 1970, Satter \& Galston 1981, Toriyama 1953).

As células epidérmicas do pulvino primário de P. pubescens mostram características ultra-estruturais indicativas de intensa atividade metabólica, incluindo dictiossomos ativos, mitocôndrias volumosas e retículo endoplasmático desenvolvido, além de vacúolos pequenos preenchidos ou não por substâncias fenólicas. A estrutura da cutícula é complexa e, provavelmente, desempenha um papel importante no funcionamento do mesmo. Sabendo-se das propriedades altamente hidrofílicas das substâncias pécticas (Mauseth 1988) e que paredes constantemente hidratadas são mais eficazes nas trocas de substâncias, bem como na absorção e retenção de água (Larcher 2000), pode-se sugerir que a presença de ramificações de substâncias pécticas na camada cuticular facilitaria as trocas entre a célula e o meio extracelular.

A presença de compostos fenólicos, especialmente taninos, nos vacúolos é uma característica marcante das células motoras em pulvinos de diferentes espécies de leguminosas (Moysset \& Simón 1991). Em P. pubescens, as reações de coloração com Azul de Toluidina e Cloreto Férrico confirmaram a presença de compostos fenólicos no vacúolo de células epidérmicas e motoras. Nota-se que esses vacúolos acompanharam as mudanças de formato das células motoras, variando de arredondados a elípticos. Variações no tamanho e formato de vacúolos taniníferos, durante movimentos do pulvino principal ou sob condições diurnas e noturnas do pulvino, também foram relatadas por diversos autores (Toriyama 1953, Toriyama \& Komada 1971, Toriyama \& Jaffe 1972, Campbell \& Thomson 1977, FleuratLessard \& Bonnemain 1978, Campbell \& Garber 1980, Fleurat-Lessard \& Millet 1984, Fleurat-Lessard 1988, Moysset \& Simón 1991). Entre as hipóteses sobre o significado funcional desses vacúolos, destaca-se aquela que sugere que o tanino pode atuar no acúmulo e liberação de íons, em particular do cálcio (Toriyama \& Komada 1971, Toriyama \& Jaffe 1972, Campbell et al . 1979, Fleurat-Lessard \& Millet 1984, Fleurat-Lessard 1988, Moysset \& Simón 1991) e potássio (Toriyama \& Komada 1971, Campbell et al. 1979, Fleurat-Lessard 

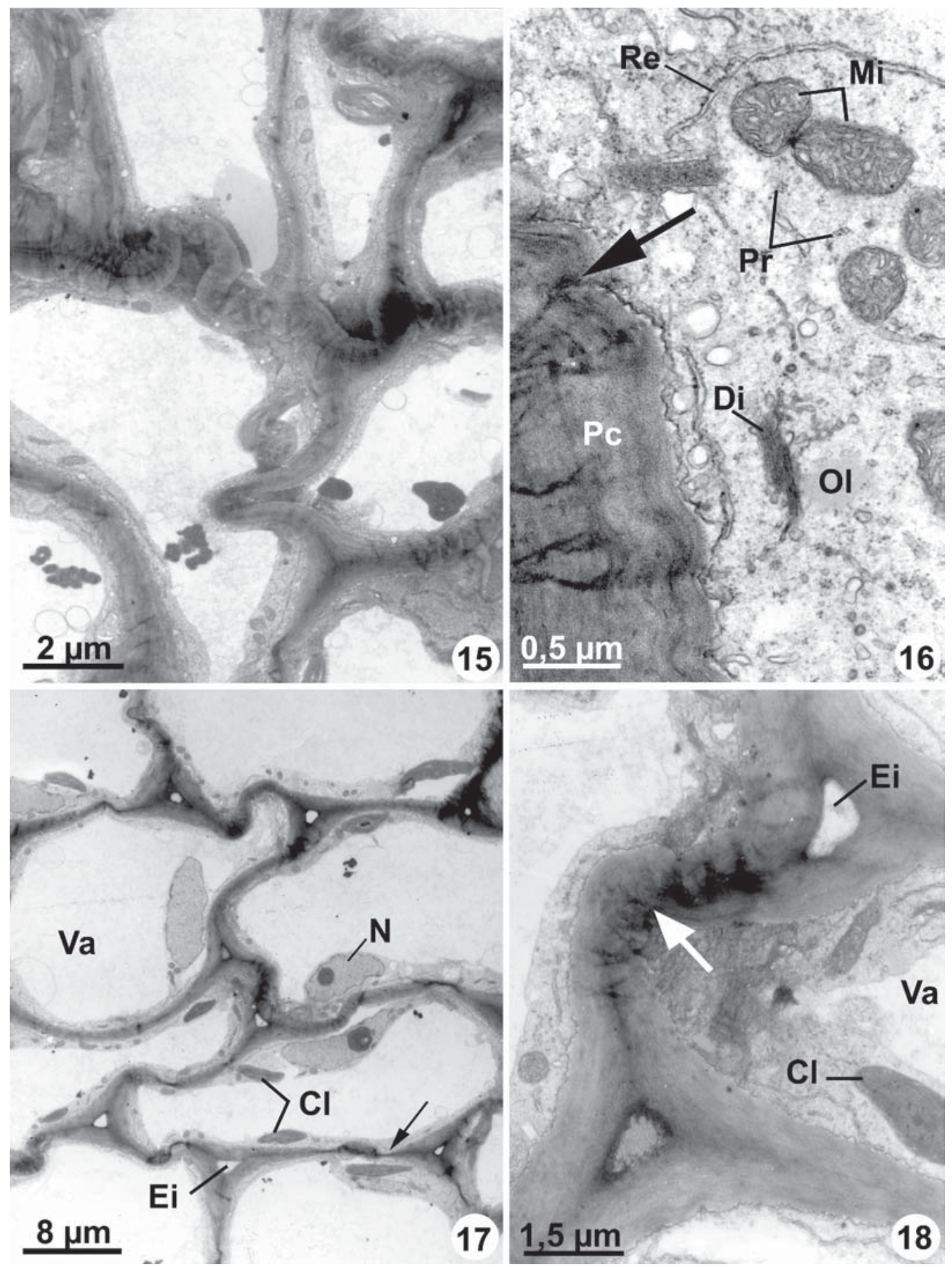

Figuras 15-18. Córtex do pulvino primário de P. pubescens (MET). 15. Células do córtex externo mostrando paredes espessas e dobradas com plasmodesmos. 16. Detalhe da figura 15 mostrando parede celular com plasmodesmos ramificados (seta), membrana plasmática sinuosa e citoplasma abundante com muitas organelas. 17. Células do córtex interno univacuoladas com paredes sinuosas e plasmodesmos (seta). 18. Detalhe da figura 17, mostrando plasmodesmos (seta) na parede sinuosa. $(\mathrm{Cl}=$ cloroplasto $; \mathrm{Di}=$ dictiossomo; $\mathrm{Ei}=$ espaço intercelular; $\mathrm{Mi}=$ mitocôndria; $\mathrm{N}$ = núcleo; $\mathrm{Ol}$ = gota de óleo; $\mathrm{Pc}=$ parede celulósica; $\operatorname{Pr}=$ polirribossomo; $\mathrm{Re}=$ retículo endoplasmático; $\mathrm{Va}=$ vacúolo).

Figures 15-18. P. pubescens primary pulvinus cortex (TEM). 15. Outer cortex cells showing thick folded walls with plasmodesmata. 16. Detail of figure 15 showing cell wall with branched plasmodesmata (arrow), sinuous plasma membrane and abundant cytoplasm with many organelles. 17. Inner cortex univacuolated cells with sinuous walls and plasmodesmata (arrow). 18. Detail of figure 17 showing plasmodesmata (arrow) in the sinuous cell wall. $(\mathrm{Cl}=$ chloroplast; $\mathrm{Di}=$ dictyosome; $\mathrm{Ei}=$ intercellular space; $\mathrm{Mi}=$ mitochondria; $\mathrm{N}=$ nucleus; $\mathrm{Ol}=$ oil drop $; \mathrm{Pc}=$ cell wall $; \mathrm{Pr}=$ polyribosomes; $\mathrm{Re}=$ endoplasmic reticulum; $\mathrm{Va}=$ vacuole $)$. 


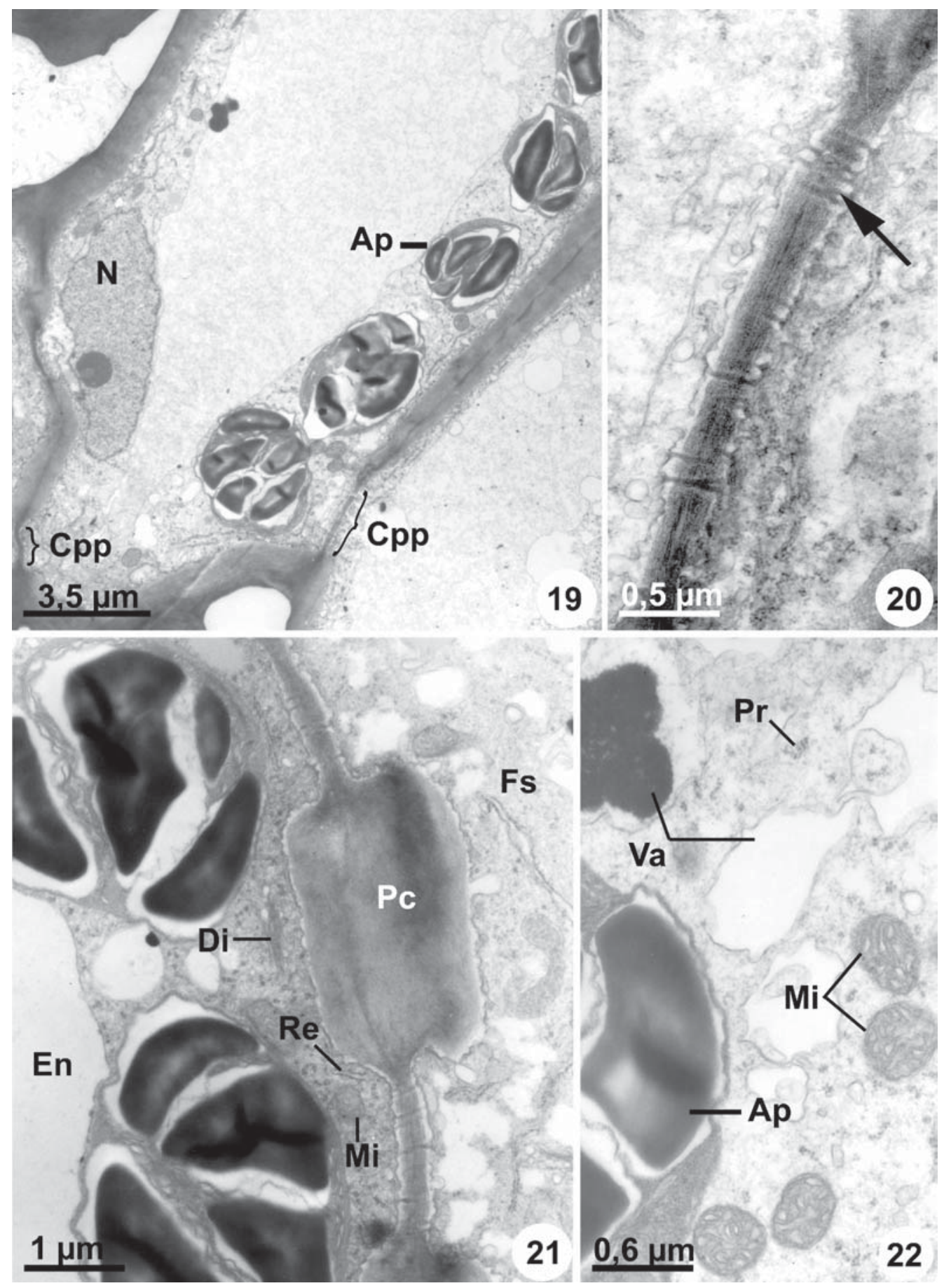

Figuras 19-22. Endoderme do pulvino primário de P. pubescens (MET). 19. Célula endodérmica mostrando núcleo e amiloplastos em lados opostos. 20. Detalhe da figura 19, mostrando plasmodesmos ramificados (seta). 21. Parte de uma célula endodérmica (à esquerda) e de uma fibra septada (à direita). Observe parede com campos de pontoação primários conectando ambas as células. 22. Detalhe da figura 21, mostrando citoplasma da célula endodérmica. ( $\mathrm{Ap}=$ amiloplasto; $\mathrm{Cpp}=$ campo de pontuação primário; $\mathrm{Di}=$ dictiossomo; $\mathrm{En}=$ endoderme; $\mathrm{Fs}=$ fibra septada; $\mathrm{Mi}=$ mitocôndria; $\mathrm{N}=$ núcleo; $\mathrm{Pc}=$ parede celulósica; $\mathrm{Pr}=$ polirribossomos; $\mathrm{Re}=$ retículo endoplasmático; $\mathrm{Va}=$ vacúolo).

Figures 19-22. P. pubescens primary pulvinus endodermis (TEM). 19. Endodermal cell with nucleus and amyloplasts on opposite sides. 20. Detail of figure 19 showing plasmodesmata branched (arrow). 21. Part of endodermal cell (on the left) and of a septate fiber (on the right). Note primary pit fields connecting both cells. 22. Detail of figure 21 showing endodermal cell cytoplasm. $(\mathrm{Ap}=$ amyloplast; $\mathrm{Cpp}=$ primary pit field; $\mathrm{Di}=$ dictyosome; $\mathrm{En}=$ endodermis; $\mathrm{Fs}=$ septate fibers; $\mathrm{Mi}=$ mitochondria; $\mathrm{N}=$ nucleus; $\mathrm{Pc}=$ cell wall; $\mathrm{Pr}=$ polyribosomes; $\mathrm{Re}=$ endoplasmic reticulum; $\mathrm{Va}=$ vacuole) . 

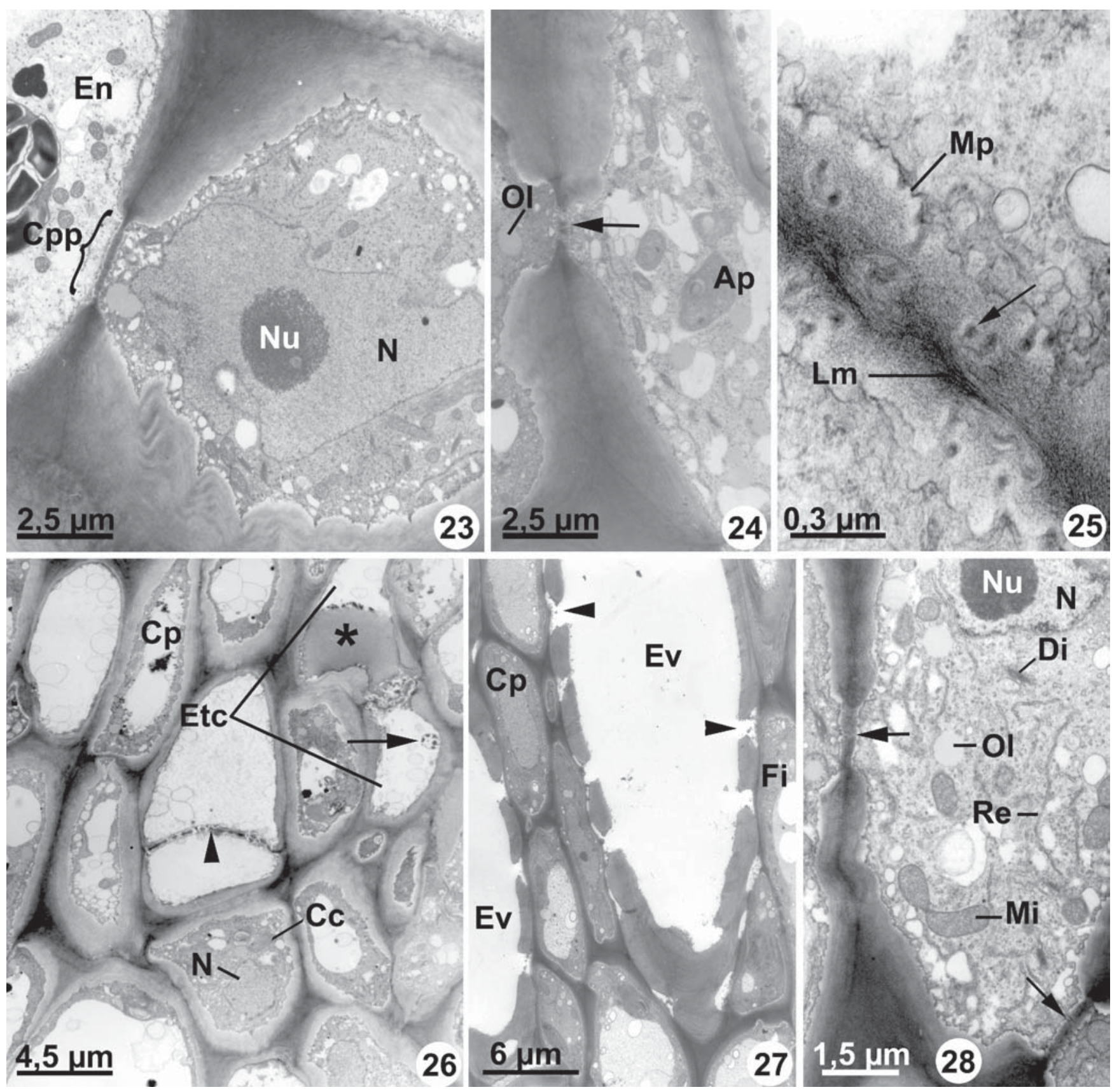

Figuras 23-28. Sistema vascular do pulvino primário de P. pubescens (MET). 23. Fibra septada, em secção transversal, mostrando camada parietal interna sinuosa, citoplasma denso, núcleo lobado com nucléolo evidente e campo de pontoação primário. 24. Fibras septadas, em secção longitudinal, conectadas por plasmodesmos (seta). 25. Septo em detalhe mostrando lamela média, parede primária com plasmodesmos (seta) e membrana plasmática sinuosa. 26. Floema. Elementos de tubo crivado com placa crivada (ponta de seta), plastídeo-P (seta) e acúmulo de material protéico $(*)$. 27. Xilema. Elementos de vaso com pontoações simples (ponta de seta) conectados às células de parênquima e elementos fibriformes. 28. Célula parenquimática, em detalhe, mostrando núcleo com nucléolo evidente, citoplasma denso rico em organelas e paredes anticlinais com plasmodesmos (setas). ( $\mathrm{Ap}=$ amiloplasto; $\mathrm{Cc}=$ célula companheira; $\mathrm{Cp}=$ célula parenquimática; $\mathrm{Cpp}=$ campo de pontoação primário; $\mathrm{Di}=$ dictiossomo $; \mathrm{En}=$ endoderme; $\mathrm{Etc}=$ elemento de tubo crivado; $\mathrm{Ev}=$ elemento de vaso; $\mathrm{Fi}=$ fibra; $\mathrm{Lm}=$ lamela média; $\mathrm{Mi}=$ mitocôndria; $\mathrm{Mp}=$ membrana plasmática; $\mathrm{N}=$ núcleo; $\mathrm{Nu}=$ nucléolo; $\mathrm{Ol}$ = gota de óleo; $\mathrm{Re}=$ retículo endoplasmático). 
1988, Moysset \& Simón 1991). A presença de compostos fenólicos no interior de vacúolos pode ainda estar relacionada com a proteção contra irradiação elevada, bem como com a manutenção da estrutura e integridade de células e tecidos em situações de estresse hídrico, entre outras funções atribuídas a estes compostos (Larcher 2000).

De acordo com Fleurat-Lessard (1988), os movimentos foliares dependem, em grande parte, da elasticidade da parede das células corticais, ou motoras. Os dados deste trabalho sugerem que os movimentos promovidos pelo pulvino primário de $P$. pubescens estão associados a mudanças tanto no compartimento apoplástico, evidenciadas por dobramentos e/ou sinuosidades da parede das células corticais, quanto no simplástico, evidenciadas por reorganização vacuolar.

Em Pterodon pubescens, uma espécie onde os folíolos apresentam movimentos lentos e reversíveis ao longo do dia (Caldas et al. 1997), as células da última camada cortical, denominada camada endodermal (Moysset \& Simón 1991), apresentam amiloplastos e cristais de oxalato de cálcio. Estas células no pulvino se caracterizam por uma polaridade estrutural evidenciada pela localização do núcleo na parte apical e dos amiloplastos na parte basal e, de acordo com FleuratLessard (1981), não intervêm no movimento do pulvino, mas sim na percepção da gravidade. A presença de cristais de oxalato de cálcio é comum na endoderme de plantas com movimentos seismonásticos mais lentos ou imperceptíveis (Schrempf et al. 1976, Morse \& Satter 1979), não sendo relatados para pulvinos com movimentos seismonásticos rápidos característicos de Mimosa pudica (Fleurat-Lessard 1988). A ocorrência de amiloplastos juntamente com cristais de oxalato de cálcio na endoderme foi igualmente observada em Robinia pseudoacacia L. (Moysset \& Simón 1991), uma espécie com movimentos nictinásticos e rítmicos em resposta a luz.

Com relação aos tecidos vasculares do pulvino de P. pubescens, embora existam diferenças estruturais em relação às espécies de leguminosa estudadas (Fleurat-Lessard \& Bonnemain 1978, Fleurat-Lessard \& Roblin 1982, Moysset \& Simón 1991), uma característica em comum é a presença de campos de pontoação primários com numerosos plasmodesmos nas células do floema e xilema, possibilitando intensa transferência lateral de substâncias. Chama a atenção no pulvino primário de $P$. pubescens a ausência de fibras lignificadas no xilema.

A presença de uma bainha de fibras septadas com protoplasto ativo e parede não lignificada ao redor do floema, é descrita pela primeira vez. Tecido semelhante pode ser observado nas ilustrações sobre a estrutura de pulvinos de diferentes espécies de leguminosas, sendo interpretado pelos diversos autores (cf. Moysset \& Simón 1991) como uma bainha de colênquima. No pulvino de $P$. pubescens as substâncias, gotas de óleo e grãos de amido, observadas nos compartimentos destas fibras indicam função de reserva (Fahn 1990); além disso, a parede não lignificada com numerosos plasmodesmos mantém a continuidade apoplástica e simplástica entre o córtex e os tecidos vasculares.

As características celulares do sistema vascular do pulvino primário de $P$. pubescens, especialmente a ausência de fibras lignificadas, o padrão de distribuição das células do parênquima radial, mostrando uma continuidade entre todos os tecidos vasculares e a intensa conexão simplástica observada, corroboram as hipóteses de alguns autores (Satter \& Galston 1981, Moysset \& Simón 1991) sobre a possível participação do cilindro central na redistribuição iônica associada com movimentos foliares.

De um modo geral, as características celulares do pulvino primário de $P$. pubescens são similares às observadas no pulvino de outras espécies de leguminosas. Os aspectos observados são intermediários entre aqueles apresentados pelo pulvino de Mimosa pudica, que se caracteriza por movimentos rápidos (Campbell \& Thomson 1977, Fleurat-Lessard 1988) e de espécies que apresentam movimentos lentos ou quase

Figures 23-28. P. pubescens primary pulvinus vascular tissues (TEM). 23. Septate fiber transversal section showing sinuous cell wall, dense cytoplasm, lobated nucleus with nucleolus and primary pit field. 24. Septate fibers longitudinal section connected by plasmodesmata (arrow). 25. Detail of septum showing middle lamella, primary cell wall with plasmodesmata (arrow) and sinuous plasma membrane. 26. Phloem. Sieve elements showing sieve plate (arrowhead), plastid-P (arrow) and proteic material accumulations $(*)$. 27. Xylem. Vessel elements with simple pits (arrowhead) connected to parenchyma cells and fibriform elements. 28. Parenchyma cell detail showing nucleus with visible nucleolus, dense cytoplasm with many organelles and anticlinal cell walls with plasmodesmata (arrows). $(\mathrm{Ap}=$ amyloplast; $\mathrm{Cc}=$ company cell; $\mathrm{Cp}=$ parenchyma cell; $\mathrm{Cpp}=$ primary pit field; Di = dictyosome; En = endodermis; Etc = sieve element; Ev = vessel element; Fi = fiber; Lm = middle lamella; $\mathrm{Mi}=$ mitochondria; $\mathrm{Mp}=$ plasma membrane; $\mathrm{N}=$ nucleus; $\mathrm{Nu}=$ nucleolus; $\mathrm{Ol}=$ oil drop; $\mathrm{Re}=$ endoplasmic reticulum). 
imperceptíveis, por exemplo, Cassia fasciculata Michx. (Roblin \& Fleurat-Lessard 1984), Albizzia julibrissin Durass. (Satter et al. 1970, Campbell \& Garber 1980), Samanea saman (Jacq.) Merr. (Satter et al. 1982) e Robinia pseudoacacia L. (Moysset \& Simón 1991). A ausência de barreiras apoplásticas, especialmente lignificação das paredes celulares e a abundância de plasmodesmos indicam que ambas as vias, apoplástica e simplástica, são usadas na redistribuição de íons durante os movimentos foliares, como sugerido por diversos autores (Morse \& Satter 1979, Campbell et al. 1981, Satter et al. 1982, Moysset \& Simón 1991).

Agradecimentos - À Fapesp pela concessão de bolsa de Iniciação Científica à segunda autora (Processo 01/01588-4) e apoio financeiro ao desenvolvimento deste trabalho (Processo 00/12469-3); à equipe técnica do Centro de Microscopia Eletrônica, Instituto de Biociências, Unesp, Campus de Botucatu, pelo auxílio no preparo das amostras.

\section{Referências bibliográficas}

CALDAS, L.S., LÜTTGE, U., FRANCO, A.C. \& HARIDASAN, M. 1997. Leaf heliotropism in Pterodon pubescens, a woody legume from the Brazilian cerrado. Revista Brasileira de Fisiologia Vegetal 9:1-7.

CAMPBELL, N.A. \& GARBER, R.C. 1980. Vacuolar reorganization in motor cells of Albizzia during leaf movement. Planta 148:251-255.

CAMPBELL, N.A. \& THOMSON, W.W. 1977. Multivacuolate motor cells in Mimosa pudica L. Annals of Botany 41:1361-1362.

CAMPBELL, N.A., STIKA, K.M. \& MORRISON, G.H. 1979. Calcium and potassium in the motor organ of the sensitive plant: localization by ion microscope. Science 204:185-187.

CAMPBELL, N.A., SATTER, R.L. \& GARBER, R.C. 1981. Apoplastic transport of ions in motor organ of Samanea. Proceedings of the National Academy of Sciences 5:2981-2984.

FAHN, A. 1990. Plant anatomy. $4^{\text {th }}$ ed. Butterworth Heinemann, Oxford.

FLEURAT-LESSARD, P. 1981. Ultrastructural features of the starch sheat cells of the primary pulvinus after gravistimulation of the sensitive plant (Mimosa pudica L.). Protoplasma 105:77-184.

FLEURAT-LESSARD, P. 1988. Structural and ultrastructural features of cortical cells in motor organs of sensitive plants. Biological Review 63:1-22.

FLEURAT-LESSARD, P. \& BONNEMAIN, J-L. 1978. Structural and ultrastructural characteristics of the vascular apparatus of the sensitive plant (Mimosa pudica L.). Protoplasma 94:127-143.
FLEURAT-LESSARD, P. \& MILLET, B. 1984. Ultrastructural features of cortical parenchyma cells ("motor cells") instamen of Berberis canadensis Mill. and terciary pulvini of Mimosa pudica L. Journal of Experimental Botany 35:1332-1341.

FLEURAT-LESSARD, P. \& ROBLIN, G. 1982. Comparative histocitology of the petiole and the main pulvinus in Mimosa pudica L. Annals of Botany 50:83-92.

FLEURAT-LESSARD, P. \& SATTER, R.L. 1985. Relationship between structure and motility of Albizzia motor organs: changes in ultrastructure of cortical cells during darkinduced closure. Protoplasma 128:72-79.

JENSEN, W.A. 1962. Botanical histochemistry: principles and practice. W.H. Freeman, San Francisco.

JOHANSEN, D.A. 1940. Plant michrotechnique. McGraw-Hill, New York.

LARCHER, W. 2000. Ecofisiologia vegetal. RiMa, São Carlos.

MAUSETH, J.D. 1988. Plant anatomy. Cummings Publishing Company, California.

MORSE, M.J. \& SATTER, R.L. 1979. Relationships between motor cell ultrastructure and leaf movements in Samanea saman. Physiology Plantarum 46:338-346.

MOYSSET, L. \& SIMÓN, E. 1991. Secondary pulvinus of Robinia pseudoacacia (Leguminosae): structural and ultrastructural features. American Journal of Botany 78:1467-1486.

O’BRIEN, T.P., FEDER, N. \& MCCULLY, M.E. 1964. Polychromatic staining of plant cell walls by toluidine blue O. Protoplasma 59:368-373.

ROBLIN, B. \& FLEURAT-LESSARD, P. 1984. A possible mode of calcium involvement in dark- and light-induced leaflet movements in Cassia fasciculata Michx. Plant Cell Physiology 25:1495-1499.

SATTER, R.L. \& GALSTON, A.W. 1981. Mechanisms of control of leaf movements. Annual Review of Plant Physiology 32:83-110.

SATTER, R.L., SABINIS, D.D. \& GALSTON, A.W. 1970. Phytochrome controlled nyctinasty in Albizzia julibrissin. I. Anatomy and fine structure of the pulvinule. American Journal of Botany 57:374-381.

SATTER, R.L., GARBER, R.C., KHAIRALLAH, L. \& CHENG, Y-S. 1982. Elemental analysis of freeze-dried thin sections of Samanea motor organs: barriers to ion diffusion through the apoplast. The Journal of Cell Biology 95:893902.

SCHREMPF, M., SATTER, R.L. \& GALSTON, A.W. 1976. Potassium-linked chloride fluxes during rhythimic leaf movement of Albizzia julibrissin. Plant Physiology 58:190-192.

TAIZ, L. \& ZEIGER, E. 1998. Plant anatomy. Sinauer Associates, Massachusetts.

TORIYAMA, H. 1953. Observational and experimental studies of sensitive plants. I. The structure of parenchymatous cells of pulvinus. Cytology 18:283-292. 
TORIYAMA, H. \& JAFFE, M.J. 1972. Migration of calcium and its role in the regulation of seismonasty in the motor cell of Mimosa pudica L. Plant Physiology 49:72-81.
TORIYAMA, H. \& KOMADA, Y. 1971. The recovery process of the tannin vacuole in the motor cell of Mimosa pudica L. Plant Physiology 36:690-697. 